\title{
The Material Analysis and Design of Desk Type Air Purifier
}

\author{
Hongyan Jin ${ }^{1, \text { a }}$, Zhiwei Zhü,b * \\ ${ }^{1}$ Changchun University, Changchun, Jilin, 130022, China \\ ${ }^{2}$ Hangzhou Normal University, Hangzhou, Zhejiang, 310036, China \\ a zhuzw5901@126.com , bzhuzw972@126.com(corresponding author)
}

Keywords: Air Purifier, Bionic Design, Material Analysis, Product Design

Abstract. This design is positioned in the outdoor air environment is increasingly deteriorated premise through the improvement or redesign, to improve people's workplace environment for desk type air purifier; and stylish innovation to meet the fast-paced city life crowd physiological and psychological needs to improve the quality of life and work purposes. Innovation of a product, in addition to hoping to facilitate people's lives, but also hope to gradually change the way people live and work to improve people's spiritual pursuit, promoting the formation of the concept of healthy living, create a harmonious and warm office environment.

\section{Introduction}

Modern people's life and work in the indoor environment all day time has reached $80 \% \sim 90 \%$, so the indoor environmental quality directly affects people's health. Indoor is not the safest place, sometimes instead of indoor air pollution is more serious. A person need $1 \mathrm{~kg}$ of food every day and $2 \mathrm{~kg}$ of drinking water, but the air is about $10 \mathrm{~kg}$, indoor air quality on people's health, comfortable living and working study efficiency is particularly important.

By the oil and automobile industry after "photochemical smog pollution", modern people are experiencing marked by "indoor environment pollution" of the third period of pollution. Probably more than thousands of indoor pollutants. International body harm to the public has taken the indoor air pollution as the biggest environmental factors.

Along with the rapid development of society and the improvement of people's life quality, health, comfortable, fashionable life and working environment is more and more attention by more and more people, especially young people. It also makes the air cleaner design for improve work environment comfort and satisfy the needs of users of the mental and psychological aspects of the role is more important.

\section{Design Research}

Air purifier is used to purify indoor air, small electrical appliances product, it is mainly used to solve because decorate or other causes of indoor air pollution problem. Due to the release of pollutants in indoor air with persistence, and the characteristics of uncertainty, so the use of air purifier to purify indoor air is internationally recognized as the way to improve indoor air quality. Air purifier on the market at present design types according to its application fields can be roughly divided into the following kinds: home air purifiers, car air purifier, medical air purifier, air purifier for engineering use, table type air purifier.

Through market research and user research and to modern way of life, work environment research found some problem. Along with the improvement of living standards of urban residents in 
our country, people is higher and higher demand for their living environment, and improving the housing conditions, increased from single living space to the luxury decoration housing, decoration materials on the indoor environment pollution is also increasing. Modern people in the working environment and lifestyle changes, pay more attention to environmental quality and the life brings relaxed and enjoy in the work. As the change of this kind of idea, air purifier is bound to be more and more become a focus of modern man. The current air purifier products mostly machine-made modelling, high cost, large volume, mobility, clean incomplete, such as adverse factors are widespread, so a green environmental protection, energy saving, pure and fresh, suitable size, convenient mobile purifier will be the aspirations of consumers.

Air purifier on the functional design should meet the needs of the vast majority of users to achieve the following: First, realize multi-function and a multi-purpose content; Second, easy to use; Third, add to the pleasures of life.

Air purifier modelling design should meet the following two points, First, as much as possible to meet user preferences of new air purifier, fashion; Second, the air cleaner overall modelling concise and easy, close to nature.

\section{Material Analysis}

Safety and health is the most basic, most important all the product requirements. Air purifier need to use safe performance of high material, which includes mechanical physics, combustion, chemical, electric performance from four aspects.

Air purifier completely using metal doesn't fit on material selection, because its quality is big, not suitable for handling. Plastic main body, local use metal is more suitable. Now there are many different kinds of plastic, have chosen the following several kinds of typical materials comparison analysis:

ABS Engineering Plastics. With good comprehensive performance, high mechanical strength, light weight, surface hardness, very smooth, easy to clean, creep resistant performance is good, but poor high temperature resistance, weather ability. It has good manufacturability and physical properties. Low foaming material of ABS resin has the property of composite wood.

Polyamide (PA). Good comprehensive performance, including mechanical properties, heat resistance, wear resistance and chemical resistance, and its low coefficient of friction, and has self lubricating performance, easy to machining, also has excellent electrical insulation properties, qualitative light, etc.

Phenolicresin(PF). High mechanical strength, electrical properties, thermal stability, flame retardancy, good corrosion resistance, abrasion resistance, lower cost, but the color is brown, can only be used for molding in dark color series of the products.

Epoxy Resin. Has excellent mechanical properties, heat resistance, good wear resistance, chemical resistance, arc resistance, resistance to high pressure leakage performance is excellent, but the cost is higher.

Polyurethane(PU). Has a good oil resistance, toughness, wear resistance and bonding, have different raw material can be made to adapt to a wider temperature range (- $50 \square, 150 \square)$ of the material. The semi-rigid polyurethane and rigid polyurethane has excellent heat resistance, weather resistance, can be used to drive low foaming wood.

FRP. It is a thermosetting plastic as substrate material of composite plastic, has high mechanical strength, weight is lighter than steel 3/4, lighter than aluminum 1/2, widely used in automotive body, fender, aircraft and other materials. 
Comparison for the above material, FRP used for air purifier body materials. First its comprehensive performance is good, high strength, ageing resistance and wear resistance are able to guarantee, also can ensure the stability of its structure. Secondly FRP is light weight, convenient user handling and carrying. From the two aspects, ensure the safety of the products and the use of the environment.

\section{Design Spread}

Target Groups Positioning. With modern social phenomenon and the market competition intensifying, product homogeneity product innovation design different way of life more and more get the attention of consumers, its content mainly includes the family way of life, consumption, leisure way, social interactions, and works in five aspects, through the analysis of target population survey, positioning for young and fashionable personage white-collar crowd: Taste, with highly artistic taste, perspective of having a unique style, sensitive, high quality, pure, like small and pure and fresh, appreciate the acme. Be fond of, like simple and delicate, don't like cumbersome. Living environment, relatively quiet, relatively gentle music, relative to the color of quietly elegant. Life attitude, is not willing to routine, sometimes burst into infinite vitality and imagination.

Image Positioning. Form as a product of the modelling of the most direct language, it is very important. "Shape" is the product of the material form, refers to the shape of the products;"State" is refers to the appearance of the product can feel spirit and state, also be understood as the expression of product appearanc. Product shape is the primary factor in the transfer product information, mainly through the product size, shape, scale and hierarchy of the influence of psychological experience, make the person produces exaggeration, implicative, fun, happy, relaxed, expression, etc. Different psychological feelings. Product configuration is the carrier of information, designers often use of peculiar modelling language, product form design. Make use of the product form unique to convey the designer's ideas and concepts. Consumer is when the choose and buy products through product shape expressed by some information content to determine whether its inner desire, and will eventually decide whether to buy.

This air purifier design of image positioning is the modelling of penguins, the reason is: The penguin modelling is nifty and lovely, was deeply loved by young group. Penguins live in the sea, give a person a kind of open and pure and fresh sense of the sea. Penguins have streamlined body, suitable for use on the product shape.The Antarctic penguins live in cold, so to be able to give a person a kind of cool feeling. See penguins in summer, people will have a kind of cool and refreshing feeling.

Function Positioning. Its using anion filter technology, can remove PM2.5.Its have health care function, can purify the blood activating cells, eliminate insomnia, enhance immunity, eliminate headache anxiety, prevent hardening of the arteries, regulate the autonomic nerve.Man-machine interface is extremely simple, its operation is simple, and to avoid wrong operation.There is a groove on the back of product, can grow green plants, such as money plant, anthurium and evergreen more practical and interesting.

Color Positioning. Black and white and grey is the color of will never be eliminated, It is in the modern home appliance was extensively used in digital products. Because these color stable, concise and easy, don't flaunt, so highly. The table type air purifier used the white, $25 \%$ grey, black, and accordingly adopted different surface processing technology to show the different modern.

Design Scheme. According to the investigation and study to determine the air purifier design thinking and design direction, positioning for young and fashionable personage white-collar crowd, 
using occasions for home or office. The other design is inspired with the appearance of the penguins, with streamline modelling is simple and easy, operation is convenient, complete basic functions, can satisfy the using a relatively small space environment. Considering the above factors determine the project of the air purifier.

The front of the air purifier is mainly by absorption and discharge hole and switch button, the left and the right of the water level observation and spillway hole, and the back of the USB charging interface, plants of the trays, is shown in Fig. 1.

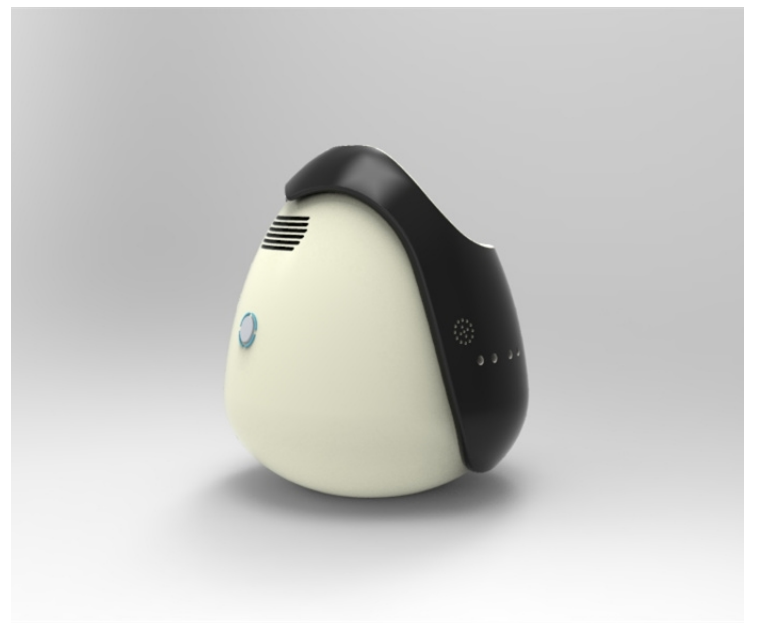

Fig. 1 Effect picture

When you use, you can click on the button to turn on the switch, it will begin to work. Air purifier is a USB interface, convenient equipped with a power adapter charging, charging can also be connected directly to the computer, in the case of can't find the socket, can charge the battery directly.

Behind the air purifier and a groove, which can be used to grow some green plants, it is not only a green plant that simple, and the plants can absorb the harmful substances in the air into material of plant, so the air purifier do not need to change filter, convenient for consumers to use, but also added a lot of colour to the home or office environment.

\section{Conclusion}

Will take the nature as templates in the design of bionic design into the small home appliance, together with the penguin this modelling and air purifier, the purpose is to give a person a kind of novel and fashionable feeling. This is not only an air purifier, it is also a natural oxygen bar, behind the whole modelling can grow green plants, make the product more vibrant. Users in the breath of the fresh air at the same time increase the experience of the flowers, convenient use, and for the user's work and the fun of life.

\section{References}

[1] Lin Ge. PR Air Purification Products Marketing Strategy Analysis. China Renmin University Press, 2010. In Chinese.

[2] Zhen Ding. The Purification and Control of Indoor Air Formaldehyde Pollution. China Public Health, 2003,19(8). In Chinese.

[3] Zhibin Xie. Product Design Principle. Mechanical Industry Press, 2011.In Chinese.

[4] Xiuzhen Zhang. Indoor Air Purifier Purify Performance Testing and Evaluation Method Environmental and Health,1998,15(5). In Chinese. 